\title{
Efeito do pré-plantio com plantas medicinais e aromáticas no controle de Plasmodiophora brassicae* $^{*}$
}

\author{
Ionete Hasse ${ }^{1}$, Louise Larissa May-De $\mathrm{Mio}^{2}$, Vismar da Costa Lima Neto ${ }^{2}$
}

\begin{abstract}
${ }^{1}$ Universidade Tecnológica Federal do Paraná, Km 01, C.p:571, Bairro Fraron, CEP 85503-390 Pato Branco, PR, Fone: (46)3220-2511, Fax: (46)3220-2500, ionetehasse@ pb.cefetpr.br. ${ }^{2}$ Departamento de Fitotecnia e Fitossanitarismo, UFPR, R. dos Funcionários, 1540, CEP 80035050, Curitiba, PR, fax: (41)33505601, maydemio@ufpr.br.

* Parte da tese do primeiro autor. Universidade Federal do Paraná (2005).

Autora para correspondência: Ionete Hasse.

Data de chegada: 19/08/2005. Aceito para publicação em: 04/05/2006.
\end{abstract}

\section{RESUMO}

Hasse, I.; May-De Mio, L.L.; Lima Neto, V da.C. Efeito do pré-plantio com plantas medicinais e aromáticas no controle de Plasmodiophora brassicae. Summa Phytopathologica, v.33, n.1, p.74-79, 2007.

A "hérnia das crucíferas" é a principal doença na produção de brássicas na Região Metropolitana de Curitiba-PR. Fatores ambientais favoráveis, ausência de cultivares resistentes e de controle químico eficiente, aliados ao plantio sucessivo de espécies da mesma família, têm colaborado para sua disseminação. Com o objetivo de controlar a doença com menor impacto ambiental, o presente estudo verificou o efeito do pré-plantio de plantas medicinais e aromáticas na redução de inóculo de Plasmodiophora brassicae. Dois experimentos foram conduzidos em casa de vegetação no Setor de Ciências Agrárias da Universidade Federal do Paraná, nos períodos de junho a novembro de 2003 e julho a dezembro de 2004. O delineamento foi inteiramente casualizado com nove tratamentos e seis repetições. As plantas utilizadas nos tratamentos foram: menta (Mentha piperita L.); alfavaca (Ocimum basilicum L.); bardana (Arctium minus Hill); calêndula (Calendula officinalis L.); cebolinha (Allium fistulosum L.); salsa (Petroselinum hortense Hoffm) e sálvia (Salvia officinalis L.), e como testemunhas foram utilizados solos sem patógeno e solo infestado, ambos em pousio. Utilizaram-se vasos contendo $3 \mathrm{Kg}$ de solo esterilizado via vapor e como inóculo de $P$. brassicae foram utilizados $2,5 \mathrm{~g}$ de galhas por vaso. A rúcula (Eruca sativa Mill) foi o hospedeiro suscetível utilizado. Após 45 dias do plantio da rúcula foram determinadas a massa aérea fresca, incidência de galhas galhas e o índice de severidade. A maior massa aérea fresca e as menores severidades foram obtidas no experimento de 2003, nos tratamentos com o pré-plantio das medicinais bardana, salsa, menta, alfavaca e cebolinha.

Palavras-chave adicionais: hérnia das crúciferas, rúcula, controle alternativo.

\section{ABSTRACT}

Hasse, I.; May-De Mio, L.L.; Lima Neto, V da.C. The effect of pre-plantation with medicinal plants in the Plasmodiophora brassicae control. Summa Phytopathologica, v.33, n.1, p.74-79, 2007.

Clubroot of crucifers is main disease in the brassica production in the Metropolitan Region of Curitiba, Paraná State. Favorable environmental factors, lack of resistant varieties and efficient chemical control along with successive plantation of the same family species have collaborated to inoculum dissemination. Aiming to control this disease with the lowest environmental impact, the present study verified the effect of preplantation medicinal and aromatic plants in the reduction of Plasmodiophora brassicae inoculum. Two experiments were carried out under greenhouse conditions at 'Ciências Agrárias' sector at 'Universidade Federal do Paraná', from June to November 2003 as well as from July to December 2004. The experiment was installed in a completely randomized design with nine treatments and six replications. Medicinal and aromatic plants used in the treatments were mint (Mentha piperita L.); basil (Ocimum basilicum L.); bardana (Arctium minus Hill); calêndula (Calendula officianalis L.); chive (Allium fistulosum L.); parsley (Petroselinum hortense Hoffm) and salvia (Salvia officinalis L.). As control samples, inoculation and infested soil, both inactive, were used. Pots with $3 \mathrm{~kg}$ of steam-sterilized soil were used, and as an inoculum of P. brassicae 2,5 $\mathrm{g}$ of galls were used per pot. Rudbeckia (Eruca sativa Mill) was the susceptible host. Forty days after rudbeckia plantation, fresh foliar mass, the incidence and disease severity index were determined. The greater fresh foliar mass and lower severity index were obtained in the 2003 experiment with the treatment pre-plantation of "bardana", parsley, mint, basil and chive. 
A Região Metropolitana de Curitiba-PR (RMC) é responsável por cerca de $70 \%$ da produção de olerícolas do estado do Paraná, abastecendo o mercado de Curitiba e outros centros consumidores do País (9).

Neste contexto, o município de Colombo se destaca, sendo responsável por 35,85 \% da produção de olerícolas da RMC, sendo crescente o interesse na produção orgânica de olerícolas. Atualmente Colombo possui 26 olericultores orgânicos certificados (1).

A demanda por produtos orgânicos de qualidade e a necessidade de um modelo agrícola que valorize a conservação dos recursos naturais têm motivado um número crescente de pequenos agricultores no município de Colombo a optarem por práticas agroecológicas menos agressivas ao meio ambiente.

Dentre as culturas de maior destaque neste sistema encontram-se as brássicas, sendo o Município de Colombo o principal produtor da RMC, responsável por $69 \%$ da produção de couve-chinesa, $67 \%$ da produção de brócolos, $62 \%$ de couve flor, $52 \%$ de rabanete, $25 \%$ da produção de rúcula e $2 \%$ da produção de repolho (20).

A produção intensiva de brássicas na RMC por vários anos tem facilitado o aumento e a disseminação da doença "hérnia das crucíferas", já que o solo contaminado com esporos de Plasmodiophora brassicae Woronin pode ser transportado pelo vento, água das chuvas e, principalmente, por equipamentos agrícolas. É provável que a disseminação possa ocorrer ainda por meio dos pés de aves e mamíferos, como também por meio das fezes desses animais, uma vez que foram encontrados esporos de resistência viáveis no esterco de bovinos (21). Também Tokeshi \& Salgado (23) assim como Maringoni (13) salientam que a disseminação ocorre pelo solo contaminado, levado por estacas, mudas, água de superfície, implementos agrícolas, homem ou outros agentes de disseminação, sendo que o último autor citado destaca a importância da utilização de mudas sadias.

O manejo inadequado, principalmente o trato dos restos culturais contaminados que são deixados no solo ou ainda incorporados, associado com o tempo de sobrevivência dos esporos que podem permanecer ativos no solo de oito a dez anos, são as principais dificuldades na diminuição do potencial de inóculo no solo. Segundo Smith et al. (21) o controle é difícil por se tratar de um patógeno de solo e por existirem poucos fungicidas eficientes, além de poucas variedades de brássicas resistentes ao patógeno. A recomendação de controle por rotação de culturas com espécies não suscetíveis e a elevação do $\mathrm{pH}$ com calagem são enfatizadas como medidas importantes para reduzir o nível de inóculo no solo. Segundo Zambolim (25) a doença é mais severa até o pH 5,7; entre 5,7 e 6,2 a severidade da doença decresce; acima de 7,8 o patógeno é complemente inibido. Entretanto, a elevação do pH nem sempre controla a doença, como constatou Schuta (19), que verificou que quando a concentração de inóculo $\left(5 \times 10^{7}\right.$ esporos $\left.\mathrm{mL}^{-1}\right)$ é elevada, o aumento do $\mathrm{pH}(7,3)$ não exerce controle efetivo sobre a severidade da doença, além do que poderão acarretar outros danos nutricionais às plantas, como a indisponibilidade de micronutrientes (boro, cobre, zinco e manganês).
$\mathrm{Na}$ região estudada, a doença tem aumentado inclusive em propriedades onde são realizados tratamentos culturais como os indicados por Tokeshi \& Salgado (23) e Maringoni (13). Provavelmente porque as rotações são feitas por um ou no máximo dois ciclos e o inóculo no solo já está em altas concentrações. Poucos estudos enfatizam a rotação de culturas com plantas antagônicas ao patógeno que pudessem favorecer a destruição dos esporos e que diminuam o potencial do inóculo. Segundo Bedendo (3), Robak (18) e Tokeshi \& Salgado (23), a menta (Mentha piperita L.) favorece a destruição dos esporos de $P$. brassicae.

Outras plantas de uso medicinal entre as quais a alfavaca (Ocimum basilicum L.), calêndula (Calendula officinalis L.), sálvia (Salvia officinalis L.), bardana (Arctium minus Hill) e cavalinha (Equisetum arvense $\mathrm{L}$.) são citadas por suas atividades antimicrobianas $(6,11,13$, $18,22)$, mas não existem estudos até o momento para avaliar os efeitos de seus exsudados radiculares na inibição de fitopátogenos, especialmente da $P$. brassicae.

Com este estudo objetivou-se avaliar o efeito do pré-plantio de plantas medicinais e aromáticas no controle de $P$. brassicae.

\section{MATERIAL E MÉTODOS}

Dois experimentos foram conduzidos em casa de vegetação da Universidade Federal do Paraná no Setor de Ciências Agrárias, nos períodos de junho a dezembro de 2003 e julho a dezembro de 2004.

\section{Características do solo}

Os dois solos utilizados nos experimentos foram coletados no Setor de Ciências Agrárias da Universidade Federal do Paraná em área de compostagem nos anos de 2003 e 2004 e tinham características químicas conforme apresentado na Tabela 1 e textura argiloso-arenoso. Foram esterilizados em forno a vapor por $6 \mathrm{~h}$, com temperatura próxima de $90^{\circ} \mathrm{C}$. Após 20 dias da esterilização, o solo foi peneirado e acondicionado em vasos de alumínio com capacidade de $3 \mathrm{Kg}$.

\section{Infestação do solo com o patógeno}

Como inóculo de $P$. brassicae foram utilizados 2,5 g de galhas por vaso, conforme preconizado por May-De Mio et al. (15), triturados em liquidificador com $50 \mathrm{~mL}$ de água esterilizadas e filtrado por meio de quatro camadas finas d tecido de musseline. Após a filtragem, o filtrado foi centrifugada (sigma 3K30) duas vezes por 10 min à $45.000 \mathrm{x}$ g . Em seguida, a suspensão de $50 \mathrm{~mL}$ foi aplicada no vaso em forma de rega. O processo foi repetido para cada vaso.

\section{Cultivo das plantas medicinais e aromáticas}

As plantas medicinais e aromáticas utilizadas foram: menta (Mentha piperita L.); alfavaca (Ocimum basilicum L.); bardana (Arctium minus Hill); calêndula (Calendula officinalis L.); cebolinha (Allium fistulosum L.), salsa (Petroselinum hortense Hoffm) e sálvia (Salvia officinalis L.), e como testemunhas foram utilizados solos sem infestação e solo

Tabela 1. Características químicas dos solos utilizados nos experimentos de pré-plantio com plantas medicinais e aromáticas no controle de Plasmodiophora brassicae em 2003 e 2004.

\begin{tabular}{|c|c|c|c|c|c|c|c|c|c|}
\hline \multirow[b]{2}{*}{ Solos } & \multirow{2}{*}{$\begin{array}{l}\mathrm{pH} \\
\mathrm{CaCl}_{2}\end{array}$} & \multirow{2}{*}{$\begin{array}{l}\mathrm{pH} \\
\mathrm{SMP}\end{array}$} & \multicolumn{4}{|c|}{------------------ $\left(\mathrm{cmol}_{d} / \mathrm{dm}^{3}\right)$------------ } & \multirow[b]{2}{*}{ K } & \multirow{2}{*}{$\begin{array}{l}\text { ppm } \\
\text { P }\end{array}$} & \multirow{2}{*}{$\begin{array}{l}\mathrm{g} / \mathrm{dm}^{3} \\
\mathrm{C}\end{array}$} \\
\hline & & & $\mathrm{Al}$ & $\mathrm{H}+\mathrm{Al}$ & $\mathrm{Ca}$ & $\mathrm{Mg}$ & & & \\
\hline 2003 & 6,50 & 6,80 & 0,0 & 3,70 & 17,25 & 5,02 & 2,16 & 201,5 & 86,2 \\
\hline 2004 & 5,80 & 6,40 & 0,0 & 3,50 & 11,63 & 5,33 & 1,58 & 140,0 & 60,6 \\
\hline
\end{tabular}




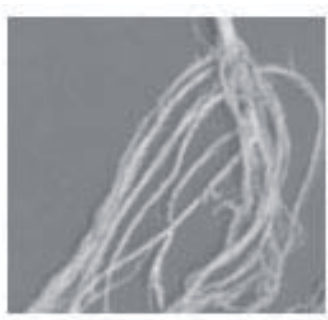

Ausente

(A)

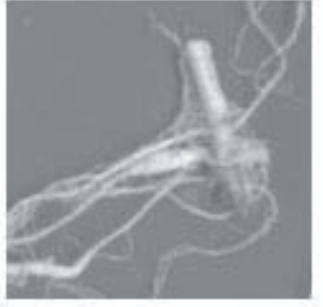

Mínima

(AB)

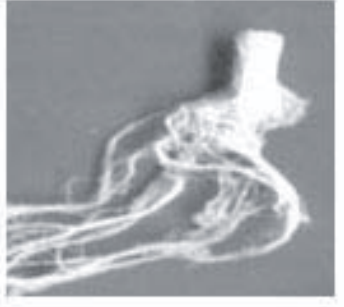

Média baixa

(B)

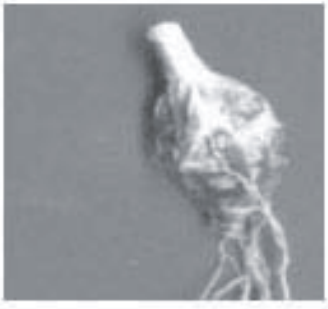

Média alta

(BC)

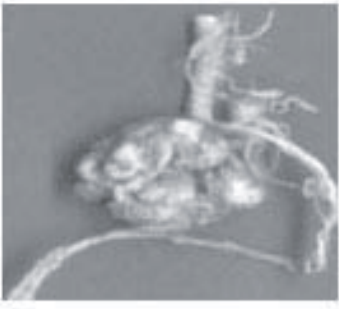

Máxima

(C)

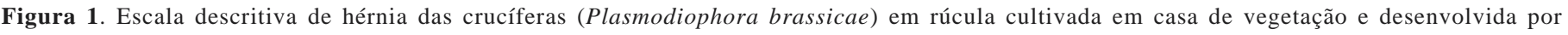
Hasse (10).

infestado, ambos em pousio durante o crescimento das plantas. $\mathrm{O}$ delineamento foi inteiramente casualizado com nove tratamentos e seis repetições, onde cada repetição constava de uma planta por vaso. Após três meses do plantio as plantas medicinais e aromáticas foram arrancadas. No experimento de 2003 esperou-se 30 dias para semear a planta teste (rúcula), e no experimento de 2004 a semeadura ocorreu após 15 dias do arranquio das medicinais e aromáticas. Uma muda de rúcula (Eruca sativa Mill) por vaso foi utilizada como hospedeiro suscetível. A rúcula foi a brássica escolhida porque apresenta ciclo de vida curto e por ser uma ótima indicadora dos sintomas da "hérnia das crucíferas".

Desenvolvimento das plantas e avaliação da incidência e severidade dos sintomas da doença nos diferentes tratamentos

Após 45 dias do plantio, a rúcula foi colhida e lavada, e, em seguida destacou-se a parte radicular ao nível do colo das plantas. A parte aérea e as radículas das plantas foram destacadas para determinação da massa aérea fresca, a incidência de galha (presença ou ausência de galhas nas raízes) e índice de severidade de acordo com a escala (Figura 1). Os resultados foram analisados pelo software SASM
- Agri $(2,4,5)$.

Avaliação do potencial ativo do inóculo no solo após realização do experimento de 2003

O solo dos diferentes tratamentos foi mantido em pousio por três meses e em seguida foi realizada a determinação do potencial de inóculo ativo pelo método de diluição em série (10).

\section{RESULTADOS E DISCUSSÃO}

\section{Desenvolvimento das plantas}

Os resultados da análise estatística para a variável massa aérea fresca em 2003 indicam que houve diferença significativa entre as plantas e a testemunha infestada (Tabela 2). Entretanto nenhum dos valores de massa aérea fresca superou os valores de massa aérea fresca da testemunha não infestada. Alguns tratamentos propiciaram um aumento da massa aérea em relação à testemunha infestada, sendo obtidos valores de 40.1, 34.6, 33.5, 29.5, 25.1 e $24.7 \%$ com as plantas bardana, menta, salsa, calêndula, alfavaca e cebolinha, respectivamente. O tratamento com sálvia propiciou o menor valor de massa aérea

Tabela 2. Massa aérea fresca de rúcula nos experimentos de pré-plantio de medicinais e aromáticas no controle de Plasmodiophora brassicae em 2003 e 2004. Curitiba-PR.

\begin{tabular}{lrr}
\hline & \multicolumn{3}{c}{ Massa aérea fresca $(\mathrm{g})$} \\
\cline { 2 - 3 } Tratamento & $2003^{*}$ & $2004^{*}$ \\
\cline { 2 - 3 } & 30 DAAM & 15 DAAM \\
\hline T. não infestada-Pousio & $16,7 \quad \mathrm{a}^{* *}$ & $10,4 \mathrm{a}$ \\
T. infestada-Pousio & $7,6 \mathrm{c}$ & $4,8 \mathrm{~b}$ \\
Sálvia & $7,0 \mathrm{c}$ & $1,3 \mathrm{c}$ \\
Salsa & $11,4 \mathrm{~b}$ & $1,1 \mathrm{c}$ \\
Menta & $11,6 \mathrm{~b}$ & $1,0 \mathrm{c}$ \\
Alfavaca & $10,1 \mathrm{~b}$ & $0,9 \mathrm{c}$ \\
Calêndula & $10,8 \mathrm{~b}$ & $1,1 \mathrm{c}$ \\
Bardana & $12,7 \mathrm{~b}$ & $0,9 \mathrm{c}$ \\
Cebolinha & $10,1 \mathrm{~b}$ & $1,6 \mathrm{c}$ \\
\hline CV $(\%)$ & 20,72 & 17,33 \\
\hline
\end{tabular}

\footnotetext{
* Médias de seis repetições.
}

**Médias nas mesmas colunas seguidas da mesma letra não diferem estatisticamente (Scott-Knott 5\%).DAAM - Dias após arranquio das medicinais e aromáticas.T. - Testemunha 
fresca de rúcula, ficando abaixo dos valores da testemunha infestada.

No ensaio de 2004 não houve diferença significativa para a variável massa aérea fresca entre os tratamentos contendo as plantas testadas (Tabela 2), porém ocorreu diferença significativa (5\% pelo teste de Scott-Knott), entre estas plantas, e as testemunhas: infestada e não infestada. Esses resultados indicam que além do inóculo, outros fatores exerceram influência no decréscimo da massa aérea fresca nos tratamentos com as plantas testadas, provavelmente efeitos de fitotoxidez dos exsudatos radiculares das plantas testadas pois em todos os casos a massa aérea da rúcula nos tratamentos com o préplantio das medicinais e aromáticas foi menor que as testemunhas. Muitos trabalhos vêm sendo desenvolvidos com extratos ou óleos essenciais de plantas medicinais no controle alternativo de doenças. Entretanto, são poucos os que mencionam a atividade dos exsudatos radiculares de plantas medicinais no controle da "hérnia das crucíferas" e são inexistentes os que abordam os efeitos fitotóxicos do pré-plantio de medicinais e aromáticas em brássicas. Nesse sentido, Cruz et al. (7) citam que plantas medicinais que possuem entre seus princípios ativos óleos essenciais mostram-se promissoras no controle de plantas invasoras. Muitas vezes este efeito alelopático provocado sobre sementes de plantas cultivadas e de importância econômica não é desejável. Para atingir esse objetivo, os autores ainda sugerem trabalhos adicionais para avaliar diferentes espécies vegetais, dosagens e métodos de aplicação ou concentrações distintas, bem como a determinação da atividade biológica dos compostos secundários.

Quando se compara os valores de massa aérea fresca dos dois períodos (Tabela 2), verifica-se que no período de 2004 os valores de massa aérea fresca foram inferiores aos de 2003. Os menores teores de Ca, K, P e C e valores de pH (Tabela 1) do solo utilizado em 2004 podem ter exercido influência na diminuição da massa aérea fresca, apesar de não estarem abaixo dos recomendados (24) e serem suficientes para um bom desenvolvimento da rúcula. Por outro lado é importante ressaltar que o menor intervalo de tempo entre o arranquio das medicinais e aromáticas e o plantio da planta teste no período de 2004 foi a mais provável causa para os decrescentes valores de massa aérea fresca, indicando que possíveis efeitos de fitotoxidez dos exsudados radiculares das plantas testadas agiram sobre o desenvolvimento da rúcula. De acordo com Ferreira \& Aquila (8) a vegetação de uma determinada área pode ter um modelo de sucessão condicionada às plantas pré-existentes e às substâncias químicas que as mesmas liberam no meio. Da mesma forma, no manejo agrícola florestal e na horticultura a ocupação prévia da área pode ter significativa influência sobre os cultivos que estão sendo instalados. Odum (17), numa revisão geral de inibidores botânicos, concluiu que os vegetais sintetizam quantidades de substâncias repelentes a outros organismos. Efeitos alelopáticos apresentam uma influência significativa sobre a seqüência de espécies e a velocidade numa sucessão vegetal e sobre a composição das espécies em comunidades estáveis.

\section{Avaliação da incidência e severidade}

A Tabela 3 apresenta os resultados da variável incidência e severidade nos experimentos realizados nos ciclos de 2003 e de 2004. Pode-se observar que em 2003 não houve diferença significativa para a variável incidência em todos os tratamentos com as plantas em relação à testemunha infestada. Entretanto, a severidade da doença foi mínima $(\mathrm{AB})$ para a bardana e média baixa (B) nos tratamentos com as medicinais sálvia, salsa, menta, alfavaca e cebolinha. Na bardana, de seis plantas avaliadas, uma teve ausência de severidade, três plantas tiveram severidade mínima (AB), dois plantas tiveram severidade média baixa (B), enquanto que na testemunha infestada de seis plantas avaliadas três apresentaram severidade máxima (C) e três tiveram severidade média alta (BC). A planta medicinal calêndula apresentou severidade média alta (BC).

No experimento de 2004 também não houve diferença significativa para a variável incidência entre as plantas testadas (Tabela 3). A severidade da doença foi mínima $(\mathrm{AB})$ para bardana e para a salsa e média baixa (B) para a sálvia, menta, alfavaca e cebolinha. A calêndula novamente apresentou severidade média alta (BC) igualando-se à testemunha infestada.

Maior intervalo de tempo entre a retirada das plantas e o plantio da rúcula observados no experimento de 2003 não comprometeu o controle da doença e possibilitou melhores resultados de massa aérea

Tabela 3. Incidência e severidade da hérnia das crucíferas em rúcula nos experimentos de pré-plantio com medicinais e aromáticas no controle de Plasmodiophora brassicae em Curitiba-PR, nos anos de 2003 e 2004.

\begin{tabular}{lcccc}
\hline Tratamentos & \multicolumn{2}{c}{$2003^{*}$} & \multicolumn{2}{c}{ 2004* $^{*}$} \\
\cline { 2 - 5 } & Incidência $^{1}$ & Severidade $^{2}$ & Incidência $^{1}$ & Severidade $^{2}$ \\
\hline T. não infestada - Pousio & $0,0 \mathrm{~b}^{* *}$ & $\mathrm{~A}$ & $0,0 \mathrm{~b}$ & $\mathrm{~A}$ \\
T. infestada - Pousio & $1,0 \mathrm{a}$ & $\mathrm{C}$ & $1,0 \mathrm{a}$ & $\mathrm{BC}$ \\
Sálvia & $1,0 \mathrm{a}$ & $\mathrm{B}$ & $1,0 \mathrm{a}$ & $\mathrm{B}$ \\
Salsa & $1,0 \mathrm{a}$ & $\mathrm{B}$ & $0,7 \mathrm{a}$ & $\mathrm{AB}$ \\
Menta & $0,8 \mathrm{a}$ & $\mathrm{B}$ & $1,0 \mathrm{a}$ & $\mathrm{B}$ \\
Alfavaca & $1,0 \mathrm{a}$ & $\mathrm{B}$ & $0,8 \mathrm{a}$ & $\mathrm{B}$ \\
Calêndula & $1,0 \mathrm{a}$ & $\mathrm{BC}$ & $1,0 \mathrm{a}$ & $\mathrm{BC}$ \\
Bardana & $0,8 \mathrm{a}$ & $\mathrm{AB}$ & $0,8 \mathrm{a}$ & $\mathrm{AB}$ \\
Cebolinha & $0,7 \mathrm{a}$ & $\mathrm{B}$ & $0,8 \mathrm{a}$ & $\mathrm{B}$ \\
\hline CV (\%) & 31,69 & & 36,65 & \\
\hline
\end{tabular}

* Médias de seis repetições.

**Médias nas mesmas colunas seguidas da mesma letra não diferem estatisticamente (Scott-Knott 5\%). ${ }^{1}$ Média da presença da doença em seis repetições. ${ }^{2}$ Escala descritiva. $\mathrm{A}=$ ausente; $\mathrm{AB}=$ severidade mínima; $\mathrm{B}=$ severidade média baixa, e $\mathrm{BC}=$ severidade média alta; $\mathrm{C}=$ severidade máxima 
Tabela 4. Incidência e severidade da hernia das crucíferas (Plasmodiophora brassicae) em rúcula, em diferentes diluições do solo e experimento de pré-plantio de medicinais e aromáticas, Curitiba-PR, 2003.

\begin{tabular}{lcccccccc}
\hline Tratamentos & \multicolumn{7}{c}{ Incidência* / Severidade** } \\
\cline { 2 - 8 } & Pousio & Alfavaca & Bardana & Menta & Calendula & Cebolinha & Salsa & Sálvia \\
\hline Solo não diluído & $8(\mathrm{~B})$ & 0 & $4(\mathrm{AB})$ & 0 & $6(\mathrm{AB})$ & $4(\mathrm{AB})$ & 0 & $1(\mathrm{AB})$ \\
Diluição 1:1 & $8(\mathrm{~B})$ & $1(\mathrm{AB})$ & $6(\mathrm{AB})$ & 0 & $4(\mathrm{AB})$ & $2(\mathrm{AB})$ & $1(\mathrm{AB})$ & $3(\mathrm{AB})$ \\
Diluição $1: 2$ & $8(\mathrm{AB})$ & $1(\mathrm{AB})$ & $5(\mathrm{AB})$ & $3(\mathrm{AB})$ & $5(\mathrm{AB})$ & $1(\mathrm{AB})$ & $3(\mathrm{AB})$ & $4(\mathrm{AB})$ \\
Diluição $1: 4$ & $8(\mathrm{AB})$ & $2(\mathrm{AB})$ & $3(\mathrm{AB})$ & $1(\mathrm{AB})$ & $3(\mathrm{AB})$ & $2(\mathrm{AB})$ & $3(\mathrm{AB})$ & $3(\mathrm{AB})$ \\
Diluição $1: 8$ & $8(\mathrm{AB})$ & $1(\mathrm{AB})$ & $1(\mathrm{AB})$ & 0 & $1(\mathrm{AB})$ & $1(\mathrm{AB})$ & $2(\mathrm{AB})$ & 0 \\
Diluição $1: 16$ & $6(\mathrm{AB})$ & 0 & 0 & 0 & 0 & 0 & 0 & 0 \\
Diluição 1:32 & $4(\mathrm{AB})$ & 0 & $1(\mathrm{AB})$ & 0 & $1(\mathrm{AB})$ & 0 & 0 & 0 \\
\hline
\end{tabular}

*Número de plantas com a doença num total de 8 repetições.

**Escala descritiva de notas: $\mathrm{A}=$ ausente de sintomas; $\mathrm{AB}=$ severidade mínima; $\mathrm{B}=$ severidade média baixa; $\mathrm{BC}=$ severidade média alta e $\mathrm{C}=$ severidade máxima.

S.I. Pousio $=$ solo infestado em pousio.

fresca (Tabela 2).

Os resultados de redução da severidade obtidos com o préplantio de medicinais e aromáticas, principalmente a bardana e a salsa que propiciaram severidade mínima e as demais que apresentaram severidade média baixa (Tabela 3), confirmam a importância da inclusão da rotação de cultura no controle da doença e, sobretudo, para a redução do dano econômico. Robak (18) obteve excelente controle da infecção causada por $P$. brassicae quando cultivou Mentha piperita e Thymus vulgaris por $2-3$ anos consecutivos, antes do cultivo de brássicas. $\mathrm{O}$ autor afirma que o completo controle da doença pode ser obtido por meio do cultivo dessas culturas por três semanas, durante a primavera.

Maciel (12), estudando o efeito da rotação de cultura de alguns plantas medicinais sobre Meloidogyne incognita raça 2, M. javanica e Pratylenchus brachyurus, constatou que a bardana propiciou efeito antagonista sobre os nematóides não permitindo sua reprodução e eliminando-os do solo e recomenda sua utilização em áreas infestadas com a finalidade de controle.

Conforme Mota \& Pessoa (16) a utilização de extratos e óleos essenciais de plantas medicinais, isolados ou em combinação com outros métodos, poderá vir a ter um importante papel no controle de fitopatógenos fúngicos, contribuindo para redução do uso de fungicidas e, conseqüentemente, um menor impacto destes ao ambiente.

Potencial de inóculo ativo de Plasmodiophora brassicae após cultivo das plantas medicinais e aromáticas.

Os resultados de incidência e severidade (Tabela 4) confirmam que o pré-plantio de medicinais e aromáticas reduziu significativamente o potencial ativo do inóculo no solo, após o segundo ciclo da rúcula, principalmente com a medicinal alfavaca, menta e salsa que apresentaram freqüência baixa de incidência e severidade mínima. No pré-plantio com sálvia e menta ocorreu ausência da doença na rúcula a partir da diluição 1:8. O pré-plantio com bardana, calêndula e cebolinha possibilitou um número maior de plantas de rúcula com a doença, mas com índice de severidade mínima $(\mathrm{AB})$. O solo infestado e não diluído apresentou um número elevado de plantas com a doença e severidade média baixa da doença na primeira diluição e severidade mínima nas demais diluições.

A ausência de incidência da doença na rúcula no solo não diluído com as plantas alfavaca, menta e salsa e na diluição $1: 1$ no tratamento com menta provavelmente é em decorrência da concentração dos exsudados radiculares ainda não totalmente diluídos que tornam o solo supressivo para a P. brassicae.

Os resultados obtidos no presente trabalho indicaram que o pré-plantio de medicinais e aromáticas apresenta resultados positivos na redução da doença, porém em determinados casos poderá ocorrer efeitos de fitotoxidez com a redução da massa aérea fresca. Entretanto, como se pode observar no experimento de 2003, o maior intervalo de tempo entre a retirada das medicinais e a implantação do plantio de brássicas evita esses efeitos indesejados.

A inclusão de espécies medicinais e aromáticas em área infestadas por P. brassicae em sistema de rotação de cultura tem um importante papel na redução do nível de inóculo no solo e vem de encontro com o crescente mercado de plantas medicinais, aromáticas e condimentares. De acordo com Correa Júnior et al.(6), o aumento na demanda de plantas medicinais, a busca de culturas alternativas porém rentáveis por parte dos agricultores e o estímulo a uma agricultura sustentável por parte da Empresa de Assistência Técnica e Extensão Rural do Paraná (EMATER-PR) fomentaram as iniciativas dos agricultores que vêm diversificando a produção, passando a cultivar, além da camomila, outras espécies exóticas e, mais recentemente, também nativas. 


\section{REFERÊNCIAS BIBLIOGRÁFICAS}

1. Almeida, L. Mudanças técnicas na agricultura: perspectivas da transição agro ambiental em Colombo-PR. 2003. 120 f. Tese (Doutorado em Meio Ambiente e Desenvolvimento) Universidade Federal do Paraná, Curitiba.

2. Althaus, R.A.; Canteri, M.G.; Giglioti, E.A. Tecnologia da informação aplicada ao agronegócio e ciências ambientais: sistema para análise e separação de médias pelos métodos de Duncan, Tukey e Scott-Knott. In: Encontro Anual de Iniciação Científica, 10., 2001, Ponta Grossa. Anais. Ponta Grossa-PR: Editora UEPG, 2001. Part..1.

3. Bedendo, I.P. Galhas de etiologia fúngica e bacteriana. In: Bergamin Filho A.; Kimati H.; Amorim L. Manual de Fitopatologias: Princípio e Conceitos. São Paulo: Agronômica Ceres, 1995. v. 1, cap.50, p. $890-897$.

4. Belan, H.C.; Canteri, M.G. - Sistema de análise e separação de médias em experimentos agrícolas. In: Encontro Anual de Iniciação Científica. 8., 2004, Anais. Londrina:UEL, 2004.

5. Godoy, C.V. SASM - Agri: Sistema para análise e separação de médias em experimentos agrícolas pelos métodos Scoft - Knott, Tukey e Duncan. Revista Brasileira de Agrocomputação, Ponta Grossa, v.1, n. 2, p.18-24, 2001.

6. Corrêa, J. C.; Graça, L. R.; Scheffer, M. C. Complexo agroindustrial das plantas medicinais, aromáticas e condimentares no estado do Paraná - diagnóstico e perspectivas. Sociedade Paranaense de Plantas Medicinais. Curitiba: EMATER, 2004. v.1, cap.4, p. $48-55$.

7. Cruz, M.E. S.; Nozaki, M.H.; Batista, M. A. Plantas medicinais e alelopatia. Revista Biotecnologia Ciência \& Desenvolvimento, Brasilia, 2000, Disponível em: <http.:// www.biotecnologia.com.br/revista/bio15/15>. Acesso em: 25 março 2004

8. Ferreira, G.A.; Aquila, M.E. A. Alelopatia: uma área emergente da ecofisiologia. Revista Brasileira de Fisiologia vegetal, Brasília, v. 12, 2000. p. 175-204, 2000. Edição Especial.

9. Hammerschmidt I. Extensão Rural: Produção de Brássicas. [out, 2004] Entrevistador: I. Hasse. Tese de Doutorado em Agronomia: Universidade Federal do Paraná. Curitiba. 2005.

10. Hasse, I. Quantificação de Plasmodiophora brassicae e uso de plantas medicinais para controle da doença. 2005. $96 \mathrm{f}$. Tese (Doutorado em Agronomia) Universidade Federal do Paraná. Curitiba.

11. Hertwig, I F.V. Plantas aromáticas e medicinais. São Paulo: Ícone, 1986. 414p.
12. Maciel, S.M. Reações de algumas plantas medicinais a Meloidogyne incognita raça 2, Meloidogyne javanica e Pratylenchus brachyurus (Nemata; Tylenchoidea). 1995. 71f (Dissertação). Escola Superior de Agronomia "Luiz de Queiroz", Universidade de São Paulo, Piracicaba.

13. Maringoni, A.C. Doenças das crucíferas. In: Rezende, J.A.M.; Camargo, L.E.A.; Filho, B.A.; Amorim, A.; Kimati, H. Manual de Fitopatologia. 3. ed. São Paulo: Agronômica Ceres, 1997. v. 2 315-324.

14. Martins, E.R.; Castro, D.M.; Castellani, D. C.; Dias, J.E. Plantas Medicinais. 4. ed. Viçosa: UFV. 2002. 220p.

15. May-De Mio, L.L.; Silva, J.; Costa Lima, M L R Z. Avaliação de diferentes formas de controle de Plasmodiophora brassicae em couve chinesa em condições de casa de vegetação. Revista do Setor de Ciências Agrárias, Curitiba, v.16, n. 1-2, p. 9-14, 1997.

16. Mota, J.C.O.; Pessoa, M.N.G. Utilização de óleo essencial e extrato foliar de Lippia sidoides Cham. no controle de fungos de sementes de graviola. In: Congresso Brasileiro de Fitopatologia, 36, 2003. Uberlândia. Brasília: SBF, 2003. Resumos Expandidos. 1 CD-ROM.

17. Odum, E.P. Ecologia. Rio de Janeiro: Koogan, 1988. 439p.

18. Robak, J. Crop rotation effect on clubroot disease decrese. Acta Horticulture n. 371, p. 223-226, 1994.

19. Schuta, L.R. Boro, nitrogênio, concentração de inóculo e pH no controle da Plasmodiophora brassicae. 2003. 99f. Tese (Doutorado em Agronomia) Universidade Federal do Paraná. Curitiba.

20. Santos, B.H. Produção de Brássicas no estado do Paraná. [abril, 2004]. Entrevistador: I. Hasse. Tese de Doutorado em Agronomia: Universidade Federal do Paraná. Curitiba. 2005.

21. Smith, I.M.; Dunez, J.; Lelliott, D.H.; Archer, S.A. European handbook of plant diseases. Oxford: Backwel Scientific, 1988 p. 243-245.

22. Souza, M.P. Constituintes químicos ativos de plantas medicinais brasileiras. Fortaleza: Universidade Federal do Ceará 1991. $416 \mathrm{p}$.

23. Tokeshi, H.; Salgado, L.C. Doenças das crucíferas. In: Kimati, H.; Amorim, L.; Bergamin Filho, A.; Camargo, L.E.A.; Rezende, J.A.M. F. Manual de fitopatologia: doenças de plantas cultivadas. São Pau1o: agronômica Ceres, 1997. v.2, 774p.

24. Universidade Federal do Paraná. Manual de diagnóstico da fertilidade e manejo dos solos agrícolas. Curitiba: Editora da UFPR, 2003. 67 p

25. Zambolim, L. Manejo integrado fitossanidade: Cultivo protegido, pivô central e plantio direto. Viçosa:Universidade Federal de Viçosa, 2001. 378 p. 